\title{
DA CENSURA E DA SOBREVIVÊNCIA PELA LITERATURA
}

Mariana Andrade da Cruz'

ohn Maxwell Coetzee - mais conhecido por J. M. Coetzee é um escritor sul-africano, agraciado com o Prêmio Nobel de Literatura em 2003. Sua primeira obra publicada por uma editora brasileira foi Desonra, pela Companhia das Letras (2000). Desde então, outros livros do autor foram trazidos ao público nacional, tais como Infância (2010), À espera dos bárbaros (2006) e Diário de um ano ruim (2008). Nascido na década de 1940 e tendo começado a sua atividade literária nos anos 70, Coetzee vivenciou os anos amargos do apartheid e fez disso material de muitos de seus romances e ensaios. Na sua escrita, seja ficcional ou ensaística, veem-se inevitavelmente as críticas à opressão, à censura e a toda forma de dominação do homem pelo homem.

Já nos anos 2000, residindo na Austrália, o autor inicia um projeto, subsidiado financeiramente pelo governo australiano, para a escrita de uma nova obra. Seu interesse pelo tema da censura existia desde os anos 90, com a publicação de Giving offense - livro que coleta textos reflexivos acerca do controle estatal sobre a arte em diferentes cenários, tais como a União Soviética pré-1989 e o Leste Europeu, além, é claro, da própria África do Sul. Produzindo boa parte de sua obra ainda à época do Partido Nacional (1948 -1990) e sob o seu crivo, Coetzee conhecia na prática os efeitos da censura, embora seus próprios romances tenham constantemente sido liberados para publicação sem maiores problemas. Tal fato sempre o intrigou. Ao receber a oferta de consultar os relatórios dos censores sobre três de seus romances, aceitou, pasmo por tal material ter sobrevivido ao regime do apartheid. Havia, nas páginas recebidas, relatórios referentes a No coração do país (1977), À espera dos bárbaros (1980) e Vida e época de Michael K (1983), obras dos anos 70 e 80.

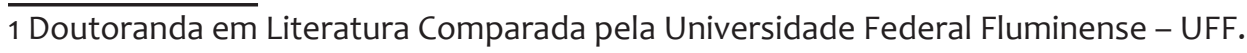


A leitura desses antigos relatórios motivou o texto de Sobre a censura, publicado pela Universidade Federal de Santa Maria (UFSM) em 2016. Trata-se da transcrição de uma palestra originalmente feita pelo autor em 2013, em Porto Alegre, e agora disponibilizada em registro impresso. As palavras de Coetzee impressionam tanto pelo fundo biográfico, que traz ao texto uma bagagem inquestionável, quanto pelas reflexões acerca da censura e de como ela era efetuada na África do Sul. Ademais, as razões dadas pelos censores para a liberação dos romances levam o autor a problematizar diferentes questões, relacionadas também ao papel da arte e à recepção artística.

O relato se inicia com a menção ao pedido de subvenção feito por Coetzee ao Conselho Australiano, "um órgão estabelecido pelo governo australiano para dar apoio financeiro a toda a sorte de artista, incluindo escritores, a fim de que pudessem continuar em seu trabalho" (p. 6 - 7). A própria existência de tal instituição choca o autor, uma vez que, em seu país natal, o apoio artístico por parte do Estado era impensável. Na verdade, conforme diz Coetzee, o ideal seria que os órgãos de patrulha sequer tomassem conhecimento de seu trabalho: "na África do Sul, tínhamos a impressão de estar com sorte se o governo ignorasse o que estávamos fazendo" (p. 7). Questionar os alicerces dessa relação difusa entre o artista e a censura é o objetivo da palestra, que prossegue apresentando um breve painel político sobre o Estado Nacional e o desenvolvimento do controle estatal no período do apartheid. Nenhum produto artístico, independentemente de sua natureza, poderia vir a público sem antes passar pelo crivo de um comitê pré-selecionado, cujos membros não eram divulgados. No caso da literatura, a restrição se tornava ainda mais fácil, por se tratar de "uma época pré-eletrônica, quando o único método prático para a transmissão de textos era o impresso, um método incômodo que pode ser facilmente interrompido e encerrado" (p. 8). Dois eram os objetivos do controle: viabilizar a prospecção de uma imagem nacionalista forte e viril, à prova de abalos que poderiam ser trazidos pela arte, e bloquear qualquer tentativa de propaganda comunista no país. 
Segundo Coetzee, ter sido um romancista iniciante nesse período histórico marcado pela censura fez com que seu interesse pelo tema fosse cada vez mais ampliado, caminhando desde o caso da África do Sul à análise de diferentes casos de censura ao longo do globo. Giving offense, publicado nos Estados Unidos em 1996, versava sobre o assunto. O autor constata que, embora a situação do escritor em seu país de origem esteja mudando para melhor, ainda se sentem os efeitos de se ter uma indústria local tão recente, posto que os mais variados manuscritos sul-africanos eram enviados para Londres, lá impressos, e de lá importados. Todo exame geral feito sobre o assunto, apresentado de maneira bastante didática e eficiente, culminará na análise de um caso particular: por intermédio do scholar Hermann Wittenberg, Coetzee teve acesso aos relatórios feitos por censores sobre três de seus romances, já aqui citados. Convém destacar que os três foram liberados para a publicação sem sofrerem nenhuma alteração ou corte em suas versões; as razões para que isso acontecesse são finalmente deslindadas - durante a leitura dos fatídicos relatórios.

Ao comentar cada um dos romances, Coetzee levanta pontos importantíssimos sobre o papel da literatura, bem como comenta aspectos da mentalidade sob o manto do apartheid que, de outra maneira, talvez não fossem tão evidentes, nem tão fortemente sentidos pelo leitor de Sobre a censura. Ao falar sobre o relatório de No coração do país, obra que apresenta variadas cenas de conotação sexual envolvendo, de modo mesclado, pessoas negras e brancas, Coetzee levanta a questão da inter-racialidade, abertamente proibida na África do Sul, inclusive por meios legais. Seguia-se, ainda, a ciência racial da Europa no século XIX, crendo-se na existência de raças elevadas e raças baixas: assim, "qualquer espécie de sexo inter-racial tornou-se subitamente ilegal e sujeita a pesadas penalidades" (p. 12). O romance em questão foi lido por três diferentes censores e aprovado mediante o seguinte registro: "uma obra difícil, obscura, multiestratificada que será lida apenas por intelectuais" (p. 14 - 15). À espera dos bárbaros, por sua vez, foi lido por um único censor, talvez pelo fato de Coetzee ter passado no teste 
inicial com No coração do país. Como seu antecessor, Espera foi criticado pelas cenas de sexo, além de um linguajar tido como inapropriado em alguns momentos; porém, foi igualmente liberado, sob o apontamento de que, "ainda que o livro possua considerável mérito literário, não possui nenhum apelo popular" (p. 15). Vida e época de Michael K, dos três o mais acintoso em suas críticas ao Estado, e de cunho abertamente político, também foi considerado publicável pela censura. $\mathrm{O}$ relatório a seu respeito apresentava a seguinte passagem:

Contém referências depreciativas ao Estado e comentários sobre suas atitudes, e também sobre as políticas e os métodos que emprega ao executar seus deveres... [Entretanto,] os leitores prováveis dessa publicação serão leitores sofisticados e judiciosos, com um interesse em literatura. Esses leitores experienciarão o romance como uma obra de arte e notarão que, embora a vida trágica de Michael K esteja situada na África do Sul, o problema dele hoje é um problema universal não limitado à África do Sul. (p. 15)

Dois pontos chamam a atenção de J. M. Coetzee ao refletir sobre a censura a que seus textos foram submetidos. $O$ primeiro está relacionado à identidade de seus censores, finalmente descoberta, mais uma vez graças aos registros. Não eram pessoas desconhecidas, ao contrário: em sua maioria, eram estudiosos e professores com os quais ele mantivera, à época, algum tipo de contato pessoal, sem desconfiar de que suas obras eram analisadas por eles. $O$ autor relata uma série de ocasiões em que teve encontros ora sociais, ora espontâneos, com os censores, destacando sempre como todos se mostravam amigáveis e cordiais em tais ocasiões. Coetzee reflete: "essas pessoas não achavam estranho ter relações sociais cordiais comigo e com outros escritores a que estavam secretamente submetendo a julgamento" (p. 21). O fato de o Diretório de Publicações ser baseado na Cidade do Cabo, lugar onde o escritor vivia à época, e cuja comunidade intelectual era enxuta, foi provavelmente responsável por tamanha coincidência. A 
surpresa inicial da descoberta foi logo substituída por uma espécie de atitude protetora para com os membros da censura: aquele julgamento especializado manobrava a Lei de Controle de Publicações, "que, em mãos mais cruas, menos versadas, talvez tivesse sido mobilizada para banir" (p. 22). Pensando nisso, o escritor traça um perfil do grupo censor: tal como o czar Nicolau I, que paradoxalmente isolou a Rússia culturalmente e agiu como vigia pessoal do poeta Alexander Pushkin, para viabilizar sua liberdade criativa dentro do escopo da lei, aquelas eram "pessoas boas trabalhando num momento histórico duro, inapreciadas, sem gratidão, de um lado salvaguardando uma ordem social frágil, por outro lado estendendo sobre o artista uma asa norteadora e protetora" (p. 24).

O segundo ponto destacado pelo autor diz respeito à receptividade da obra literária. Os três romances apresentavam, para os censores, como característica comum, o fato de que eram considerados inofensivos - ou perigosos em uma medida mínima, o que não justificaria seu bloqueio - por interessarem a um público específico e bastante restrito, composto por intelectuais, sem jamais ameaçar um alcance sobre a maior parte da população. "'Esses livros de J. M. Coetzee não precisam ser banidos', disseram, com efeito, meus censores, 'pois eles serão lidos tão somente por profissionais da literatura"' (p. 22), registra o autor. É ao debater esse aspecto que o texto de Coetzee alcança seu ponto máximo: ao depor sobre a suposta diferença entre livros de massa e livros de apelo minoritário, conceito que se delineou como crucial para a censura da época, Coetzee marca as falsas certezas fundeadas nesse imediatismo. Como ele aponta, "um livro que muda a história não precisa ser um livro que traz a notícia fresquinha e que é devorado pelas massas, as quais imediatamente são enfeitiçadas por ele, eletrizadas para a ação. Os processos da história são muito mais indiretos do que isso e levam muito mais tempo" (p. 26). Para exemplificar tal certeza, o autor remete a uma personagem de À espera dos bárbaros, o coronel Joll, cujo perfil se assemelha diretamente aos torturadores da Special Branch do apartheid. O registro literário teria o 
poder de eternizar uma prática política por intermédio de uma figura fictícia, mas facilmente reconhecível para quem detivesse um certo conhecimento histórico. De fato, essa conexão era de tal maneira evidente que jamais passaria despercebida pelo leitor comum, e muito menos pelo olhar experimentado do censor. Ao pensar nisso, Coetzee vincula o segundo ao primeiro ponto, novamente pensando na figura do censor não como um inimigo, mas como alguém cujo julgamento propositalmente encontrou brechas, permitindo que a obra viesse a público. Essa relativização do papel da censura é o grande trunfo do texto, justamente com a afirmação final, que assinala a sobrevivência pela literatura: "Quando nos é negado um objeto indesejado, encontramos outro. Quando mais as coisas mudam, mais se mantêm as mesmas" (p. 29).

A edição feita pela Editora da UFSM conta, ainda, com um posfácio redigido por Kathrin Holzermayr Rosenfield e Lawrence Flores Pereira, que funciona muito bem como uma leitura complementar. Nele, a dupla apresenta diferentes enfoques dados pelo sul-africano ao tema da censura, em variados textos teóricos, mas, sobretudo, em Giving offense, sua mais famosa obra a respeito. O posfácio também se debruçará sobre a fortuna literária do escritor, em uma abordagem que pode auxiliar o leitor que, porventura, deseje conhecer mais sobre tais obras. Entretanto, como matriz impactante, apenas o relato de Coetzee bastaria. Terminamos a leitura do breve texto arrebatados por cada uma de suas palavras. Infelizmente, o autor não se detém muito sobre as reflexões que suscita. Consideremos que esses apontamentos foram, originalmente, uma palestra de cerca de 50 minutos, a qual, por força do tempo exíguo, teria de conter o muito em poucas palavras. Fica, porém, o registro do seu relato, como um ponto de tensão a ser destrinchado pelo leitor. Trata-se de leitura obrigatória não só para aqueles interessados na fortuna literária de Coetzee, no tema da censura ou nas motivações históricas que envolveram o período do apartheid, mas para todos aqueles que amam literatura e sabem como ela pode representar resistência e sobrevivência. 


\section{REFERÊNCIA BIBLIOGRÁFICA}

COETZEE, J. M. Sobre a censura. Trad. Lawrence Flores Pereira. Santa Maria: UFSM, 2016. 